\title{
Genetic Polymorphisms in CYP1A1, GSTM1, GSTP1, GSTT1, NAT1 and NAT2 and Oral Cavity Cancer Risk among Filipinos
}

\author{
Eva Maria C. Cutiongco-De La Paz, ${ }^{1}$ Corazon A. Ngelangel,, 23 Alfredo Y. Pontejos,${ }^{4}$ Carmencita D. Padilla, ${ }^{1}$ \\ Catherine Lynn T. Silao, ${ }^{1}$ Regie Lyn S. Cortez,${ }^{4,5}$ Frances C. Rocamora, ${ }^{1}$ Arsenio C. Cabungcal, ${ }^{4}$ \\ Nathaniel W. Yang, ${ }^{4}$ Gil M. Vicente ${ }^{6}$ and Mark U. Javelosa ${ }^{3}$ for the Philippine Cancer Genetics Study Group \\ ${ }^{1}$ Institute of Human Genetics, National Institutes of Health, University of the Philippines Manila \\ ${ }^{2}$ Institute of Clinical Epidemiology, National Institutes of Health, University of the Philippines Manila \\ ${ }^{3}$ Section of Medical Oncology, Department of Medicine, College of Medicine and Philippine General Hospital, University of the Philippines Manila \\ ${ }^{4}$ Department of Otorhinolaryngology, College of Medicine and Philippine General Hospital, University of the Philippines Manila \\ ${ }^{5}$ Philippine National Ear Institute, National Institutes of Health, University of the Philippines Manila \\ ${ }^{6}$ Department of Otorhinolaryngology, Jose R. Reyes Memorial Medical Center, Rizal Avenue, Sta. Cruz, Manila
}

\begin{abstract}
Polymorphisms in metabolic genes have been shown to modulate susceptibility to oral cavity cancer. Cases ( $n=176)$ and controls $(\mathrm{n}=317$ ) from the Filipino population were genotyped for selected polymorphisms in CYP1A1, GSTM1, GSTP1, GSTT1, NAT1 and NAT2. Medical and diet histories, occupational exposure and demographic data were also collected for all subjects. The CYP1A1 $1 / \mathrm{m} 1$ genotype is protective against oral cancer, while being homozygous for the GSTP1 c.313G genotype and heterozygous for the $N A T 1^{*} 10$ allele are significant risk factors for oral cancer. Genetic subgroup analyses suggest that the risk conferred by homozygosity for the GSTP1 variant was only significant among $N A T 1^{*} 10$ homozygotes and nonhomozygotes for the CYP1A1 $\mathrm{m} 1$ allele. The risk from heterozygosity for the $N A T 1^{*} 10$ allele was limited to subjects who were not homozygous for the GSTP1 c.313G polymorphism. After adjusting for environmental variables, the homozygous GSTP1 c.313G genotype remained a significant oral cancer risk modifier, together with environmental risk factors, such as smoking, passive smoking, inverted smoking and tobacco chewing, and environmental protective factors, i.e. moderate consumption of fish sauce (patis) and shrimp paste (bagoong). The GSTP1 c.313G polymorphism increases susceptibility for oral cavity cancer in the Filipino population.
\end{abstract}

Key Words: Filipinos, genetic polymorphisms, metabolic enzyme, oral cavity cancer, risk factor, susceptibility

\section{Introduction}

Worldwide about 400,000 cases of oral cavity and pharyngeal cancer and 160,000 cases of laryngeal cancer are reported annually. ${ }^{1}$ In the Philippines, the oral cavity ranks as the $15^{\text {th }}$ most common cancer site among women (age-

Corresponding author: Eva Maria C. Cutiongco-dela Paz, MD

National Institutes of Health

University of the Philippines Manila

625 Pedro Gil street, Ermita, Manila 1000 Philippines

Telephone: +6325257459

Fax no.: +6325257459 or +6325269997

E-mail: ecutiongcodelapaz@upm.edu.ph standardized rate incidence: 1.7$), 10^{\text {th }}$ among men (agestandardized rate incidence: 2.6$)$, and $15^{\text {th }}$ for both sexes (age-standardized rate incidence: 2.1 ). ${ }^{2}$

Risk factors for oral cavity cancer include alcohol consumption, smoking, tobacco and betel nut chewing, as well as occupational exposure to certain chemicals. ${ }^{1}$ However, the carcinogenic risk attributed to these compounds can also be modified by genetic susceptibility factors in the host, such as genetic polymorphisms, that potentially predict cancer risk. ${ }^{3}$ Phase I and Phase II metabolizing enzyme genes encode proteins that catalyze either the effective detoxification of various endogenous and exogenous substrates into harmless compounds, or their metabolic activation into toxic and carcinogenic products. Many of these genes are functionally polymorphic due to different allelic variants. The phenotypic differences in these enzymes could, in turn, result in varied susceptibility to cancer among individuals. ${ }^{4}$ Allelic variants in genes from the Cytochrome P450, Glutathione-S-Transferase and Nacetyltransferase superfamilies can significantly influence risk of developing oral cavity cancer. 5,6,7

Cytochrome P450 (CYP) enzymes are responsible for catalyzing the carcinogenic activation of various endobiotics (i.e. steroids and fatty acids) and xenobiotics found in the environment or our diet (i.e. polycyclic aromatic hydrocarbons, aromatic amines and mycotoxins). ${ }^{8,9}$ In some cases, CYP enzymes are responsible for detoxifying certain metabolites. ${ }^{10}$ Among the CYP genes, CYP1A1 variants have been associated with lung, esophageal, and head and neck cancers. There are two CYP1A1 polymorphisms that have been found to increase the enzyme's inducibility and catalytic activity: the p.Ile462Val polymorphism in CYP1A1 exon 7 , called the $m 2$ allele (g.4889A $>\mathrm{G})$; and the T-to-C transition in the $3^{\prime}$ non-coding region of the genedetectable by MspI restriction, named the $m 1$ allele (g.6235T>C). $5,8,11,12,13$

The Gluthathione S-transferase (GST) genes are primarily involved in cellular detoxification by preventing 
the attack of reactive electrophiles on macromolecules. ${ }^{14}$ These multifunctional phase II enzymatic proteins catalyze the conjugation of glutathione to carcinogens and their reactive intermediates, rendering them more water-soluble to facilitate subsequent excretion. ${ }^{15,16}$ Increased cancer risk has been associated with GST genotypes harboring homozygous null alleles, as in the case of GSTM1 and GSTT1, and those that code for low activity variants, which has been observed for GSTP1. ${ }^{17,18,19}$

The $\mathrm{N}$-acetyltransferase genes NAT1 and NAT2 perform $\mathrm{N}$-acetylation, O-acetylation, and N,O-acetyltransfer which activate or deactivate aromatic amines; Activation of these species results in the formation of acetoxy esters that decompose into highly electrophilic aryl nitrenium ions capable of initiating carcinogenesis. Polymorphic variants of NAT1 and NAT2 have different rates of acetylation. ${ }^{20,21}$ Different alleles of both genes, in particular the $N A T 1^{*} 10$ allele and the NAT2 slow acetylator genotypes, have been shown to confer increased risk for oral cavity cancer. ${ }^{22,23,24}$ In a recent meta-analysis, NAT2 slow acetylator polymorphisms have been found to potentially increase oral cancer risk among Asians but not among Caucasians or other races. $^{25}$

To our knowledge, this is the first report of the association between metabolic enzyme gene polymorphisms and oral cavity cancer within the Filipino population. Specifically the Phase I and II metabolic enzyme genes CYP1A1, GSTM1, GSTP1, GSTT1, NAT1 and NAT2 were genotyped in oral cavity cancer patients and controls and the cancer risk conferred by single genes and multiple genes taken together was estimated. We also investigated the interaction of these polymorphisms with environmental risk factors for oral cavity cancer.

\section{Materials and Methods}

\section{Subject Population}

Prior to study initiation, approval was obtained from Ethics Review Committee of the Research Implementation and Development Office, College of Medicine, University of the Philippines Manila. Informed consent was obtained from all subjects. A total of 176 cases with histopathologically confirmed carcinoma of the oral cavity and 317 healthy controls were enrolled in the case-control study. The patients were recruited from four tertiary hospitals (Philippine General Hospital (PGH), Jose R. Reyes Memorial Medical Center (JRRMMC), East Avenue Medical Center (EAMC) and Ospital ng Maynila Medical Center (OMMC) from June 2002 to September 2008. The inclusion criteria was the presence of histopathologically confirmed carcinoma of the oral cavity (any age, any stage, any Eastern Cooperative Oncology Group) and no history of chemotherapy or radiotherapy prior to study enrolment. The inclusion criterion for the controls was the absence of a prior history of and clinical signs of cancer. The controls (age-5 years-interval-matched; sex-matched) were randomly selected from the same hospitals as the cases during the same time period.

\section{Data Collection}

All individuals were interviewed by trained health workers using a questionnaire and standardized interview and measurement techniques. Information on multiple variables were collected, including age, gender, occupation, tobacco and betel nut chewing habits, family history of head and neck cancer, oral contraceptive use, diet (consumption of: alcohol, canned meat, fish sauce (patis), shrimp paste (bagoong), vegetables, scalding hot food, preserved foods, smoked foods, salted foods), and occupational exposure (exposure to: moldy food, pesticides, vinyl chloride, benzene, UV sunlight, coal carbonization, and wood dust). The questionnaire and the interview technique were pretested among a group of Filipino patients and were modified accordingly. Blinding of interviewers as to case-control status could not be completely done since some tumors were visible.

\section{DNA Isolation}

Four milliliters of peripheral blood was collected from each subject for molecular genotyping. Genomic DNA was extracted from whole blood samples of recruited cases and controls using the QIAamp® Blood Midi Kit Spin Protocol (Qiagen $\mathrm{GmbH}$, Hilden, Germany). The DNA extracts were subsequently stored at $-20^{\circ} \mathrm{C}$.

\section{Molecular Genotyping}

Polymorphisms for CYP1A1, GSTM1, GSTT1, GSTP1, NAT1 and NAT2 genes were detected using polymerase chain reaction (PCR) and PCR-restriction fragment length polymorphism (RFLP). PCR and RFLP products were visualized using agarose gel electrophoresis. Genotyping methods by PCR-RFLP were verified by direct sequencing.

CYP1A1.The $m 1$ allele (g.6235T $>C$ ) at the 3 ' flanking region of the gene was ascertained with MspI while the $m 2$ allele at exon 7 was detected with NcoI using PCR-RFLP as previously described. $8,6,27$

GSTM1 and GSTT1. The presence of at least one allele of GSTM1 and GSTT1 was determined using PCR. ${ }^{8}$ As an internal control, exon 7 of the CYP1A1 gene was coamplified for each reaction using previously published primers. $^{28}$

GSTP1. The c.313A $>\mathrm{G}$ polymorphism in exon 5 was ascertained using PCR-RFLP with Alw26I. ${ }^{18}$

NAT1. Detection of NAT1 alleles was performed using PCRRFLP with $M b o I I$ for $N A T 1^{*} 4$, and $N A T 1^{*} 11$. Allele-specific 
PCR was performed using NAT1*3-specific and NAT1*10specific primers to distinguish between the two alleles. ${ }^{29}$ As an internal control for allele-specific PCR, $\beta$-globin was coamplified using previously published primers. ${ }^{8}$

NAT2. Detection of NAT2alleles was performed using the PCR-RFLP strategy by Hubbard et al..$^{30}$

\section{Statistical Analysis}

For the environmental variables, statistical analysis was done using Stata Program version 9.0, while SPSS 14.0 software was used for statistical analysis of genetic variables. Age-and sex-matched pairs were analyzed including multiple controls per case within an age-group. Comparison of characteristics between groups was carried out through $\chi^{2}$ tests for genetic variables, McNemar's test for environmental variables, and independent t-tests for continuous (environmental) variables. Univariate conditional logistic regression analyses for environmental and genetic variables were initially carried out separately using simple conditional logistic regression to assess the significance of each independent variable or risk factor for cancer by cancer site. All environmental factors that were significant at 0.2 level in the univariate analyses were included in the multivariate conditional logistic regression model. All environmental factors that were significant in the multivariate analysis were included in multivariate logistic regression with statistically significant genetic variables to test for gene-environment interactions.

For diallelic genes GSTP1, CYP1A1 and CYP2E1 genotypes were tested for Hardy-Weinberg Equilibrium (HWE). Only four of 26 known NAT1 alleles and six of 62 known NAT2 alleles were tested, thus genotype frequencies for both genes are expected to deviate from HWE. ${ }^{31}$

\section{Results}

A total of 176 cases and 317 controls were available for study (Table 1). There were 210 males (42.6\%) and 283 females $(57.4 \%)$. Median age range for the whole group was 50-54 years old, 45-49 for the controls and 55-59 for the cases. Age-matched logistic regression of environmental factors revealed that current smoking, former smoking, passive smoking, inverted smoking, tobacco chewing, betel quid chewing, consumption of scalding food ( $>5$ days/month), consumption of salted food ( $>5$ days/month), UV sunlight exposure $(\geq 7 /$ month) are significant risk factors for oral cancer; while canned meat consumption (daily to $2 x /$ month), using fish sauce or patis (daily to $2 x /$ month) and shrimp paste or bagoong (daily to $2 \mathrm{x} / \mathrm{month}$ ) were significant protective factors (Table 2). After multivariate analysis, current smoking (OR 1.99; 95\%CI: 1.20, 3.31), passive smoking (OR 2.81; 95\%CI: 1.57, 5.06), inverted smoking (OR 3.22; 95\%CI: 1.28, 8.08) and chewing tobacco (OR 5.16; $95 \%$ CI: 1.37, 19.50) were found to increase susceptibility for oral cancer, while use of shrimp paste (bagoong) (OR 0.48; 95\%CI: 0.27, 0.84) and fish sauce (patis) (OR 0.44; 95\%CI: $0.25,0.78$ ) were significant protective factors (Table 2).

Table 1. Age and sex distribution of oral cavity cancer cases and controls

\begin{tabular}{|c|c|c|c|c|c|}
\hline \multirow{2}{*}{ Age } & \multicolumn{2}{|c|}{ Control } & \multicolumn{2}{|c|}{ Case } & \multirow{2}{*}{ Total } \\
\hline & Male & Female & Male & Female & \\
\hline$<20$ & 4 & 8 & 0 & 0 & 12 \\
\hline $20-24$ & 8 & 12 & 3 & 0 & 23 \\
\hline $25-29$ & 8 & 6 & 0 & 0 & 14 \\
\hline $30-34$ & 10 & 17 & 4 & 3 & 34 \\
\hline $35-39$ & 13 & 13 & 3 & 1 & 30 \\
\hline $40-44$ & 18 & 22 & 7 & 3 & 50 \\
\hline $45-49$ & 9 & 26 & 10 & 5 & 50 \\
\hline $50-54$ & 13 & 33 & 19 & 9 & 74 \\
\hline $55-59$ & 9 & 16 & 13 & 11 & 49 \\
\hline $60-64$ & 10 & 16 & 12 & 15 & 53 \\
\hline $65-69$ & 6 & 13 & 9 & 15 & 43 \\
\hline $70-74$ & 8 & 8 & 5 & 7 & 28 \\
\hline $75-79$ & 2 & 3 & 4 & 11 & 20 \\
\hline$>79$ & 2 & 4 & 1 & 6 & 13 \\
\hline Total & 120 & 197 & 90 & 86 & 493 \\
\hline
\end{tabular}

Table 2. Age- and sex-matched univariate logistic regression analysis for environmental factors and oral cavity cancer ${ }^{a}$

\begin{tabular}{|c|c|c|}
\hline Variable & OR & OR 95\% CI \\
\hline Nonsmoker & 1.00 & \\
\hline Current smoker ${ }^{\mathrm{b}}$ & 3.12 & $1.79,5.43$ \\
\hline Ex-smoker & 2.26 & $1.28,4.00$ \\
\hline Chew tobacco ${ }^{b}$ & 6.04 & $1.73,21.07$ \\
\hline Inverted cigarette smoker ${ }^{b}$ & 4.45 & $1.97,10.04$ \\
\hline Passive smoker ${ }^{\mathrm{b}}$ & 3.97 & $2.32,6.81$ \\
\hline Non-drinker, alcohol & 1.00 & \\
\hline Current drinker, alcohol & 1.19 & $0.67,2.11$ \\
\hline Ex-drinker, alcohol & 0.91 & $0.48,1.74$ \\
\hline Canned meat eater (daily-2/month) & 0.42 & $0.26,0.67$ \\
\hline Fish sauce (patis) user (daily-2/month) ${ }^{\mathrm{b}}$ & 0.24 & $0.15,0.37$ \\
\hline Shrimp paste (bagoong) user (daily-2/month) ${ }^{b}$ & 0.26 & $0.17,0.40$ \\
\hline Vegetable eater $(\geq 1 /$ week $)$ & 0.64 & $0.30,1.36$ \\
\hline Family history head \& neck cancer, $1^{\text {st }}$ degree & 0.76 & $0.12,4.80$ \\
\hline Scalding hot-food taker ( $>5$ days/month) & 1.73 & $1.13,2.65$ \\
\hline Preserved food (nitrite-treated) eater ( $>5$ days/month) & 0.69 & $0.44,1.08$ \\
\hline Smoked food eater (> 5 days/month) & 1.52 & $0.95,2.44$ \\
\hline Salted food eater (> 5 days/month) & 2.71 & $1.61,4.56$ \\
\hline Moldy food exposure ( $\geq 1$ / month) & 0.69 & $0.46,1.05$ \\
\hline Oral contraceptive use ( $\geq 1$ / year) & 0.56 & $0.22,1.42$ \\
\hline Pesticide exposure ( $\geq 1 /$ week) & 1.64 & $0.79,3.39$ \\
\hline Vinyl chloride occupational exposure & 1.00 & $0.24,4.22$ \\
\hline Benzene occupational exposure & 0.69 & $0.16,2.96$ \\
\hline UV sunlight exposure ( $\geq 7 /$ month) & 2.01 & $1.23,3.29$ \\
\hline Wood dust occupational exposure & 2.63 & $0.96,7.20$ \\
\hline Betel quid chewing & 6.94 & $2.01,23.93$ \\
\hline \multicolumn{3}{|c|}{$\begin{array}{l}\text { aPreviously published in Acta Medica Philippina. Source: Ngelangel A, Javelosa MA, } \\
\text { Cutiongco-de la Paz, EM and The Philippine Cancer Genetics Study Group. } \\
\text { Epidemiological Risk Factors for Cancers of the Lung, Breast, Colon-rectum E Oral } \\
\text { cavity: A Case-Control Study in the Philippines. Acta Medica Philippina 2009; } \\
\text { 43(4):29-34 } \\
\text { 'Environmental factors that remained significant after age and sex-matched } \\
\text { multivariate logistic regression: current smoking (OR 1.99; 95\% CI 1.20-3.31), } \\
\text { passive smoking (OR 2.81; 95\% CI 1.57-5.06), tobacco chewing (OR 5.16;95\% CI } \\
\text { 1.37-19.5), and inverted smoking (OR 3.22; 95\% CI 1.28-8.08), consumption of } \\
\text { shrimp paste (bagoong), daily-2/month (OR 0.48; 95\% CI 0.27-0.84), and } \\
\text { consumption of fish sauce (patis), daily-2/month (OR 0.44;95\% CI 0.25-0.78) }\end{array}$} \\
\hline
\end{tabular}


For the genetic factors, age- and sex-adjusted univariate logistic regression showed that cancer risk increases twofold with the GSTP1 c.313A $>\mathrm{G}$ homozygous genotype (OR 2.07; 95\% CI: 1.03, 4.16) and the GSTP1 c.313A>G allele, recessive model (OR 2.26; 95\%CI: 1.15, 4.44) (Table 3). In multivariate analysis, the GSTP1 variant homozygous genotype remains a significant risk factor (OR 2.98; 95\%CI: 1.35, 6.57) (Table 4). Among the NAT genes, univariate analysis (dominant model) identified only the NAT1*10 allele (OR 1.78; 95\% CI 1.05-3.04) as a significant risk factor, while the $N A T 1^{*} 10$ heterozygote genotype increased cancer susceptibility based on both univariate (OR 1.86; 95\% CI 1.04-3.34) (Table 3) and multivariate (OR 2.15; 95\% CI 1.163.96) analyses (Table 4). Among the polymorphisms studied, only CYP1A1 polymorphisms were found to protect against oral cavity cancer. From univariate analyses, the CYP1A1m1/m1 genotype (OR 0.50; 95\%CI: $0.28,0.88$ ) and $m 1$ allele (dominant model) (OR 0.66; 95\%CI: 0.45, 0.97), as well as heterozygosity for the CYP1A1 $\mathrm{m} 2$ allele (OR 0.66; 95\%CI: $0.44,0.99)$ reduced risk for oral cancer (Table 3$)$. However, after multivariate analyses, only the $C Y P 1 A 1 \mathrm{~m} 1 / \mathrm{m} 1$ genotype remained significantly protective (OR 0.45 ; 95\% CI 0.24-0.85) (Table 4).

Table 3. Age- and sex-adjusted univariate logistic regression analyses by oral cavity cancer status

\begin{tabular}{|c|c|c|}
\hline Variable $^{a}$ & OR & OR $95 \% \mathrm{CI}$ \\
\hline GSTM1 null & 0.88 & $0.60,1.29$ \\
\hline GSTT1 null & 1.02 & $0.70,1.48$ \\
\hline GSTP1 c.313A>G homozygote & 2.07 & $1.03,4.16$ \\
\hline GSTP1 c.313 A>G heterozygote & 0.82 & $0.55,1.21$ \\
\hline GSTP1 c.313 A>G allele (dominant) & 0.96 & $0.66,1.38$ \\
\hline GSTP1 c.313 A>G allele (recessive) & 2.26 & $1.15,4.44$ \\
\hline CYP1A1 g. 6235T>C (m1) homozygote & 0.50 & $0.28,0.88$ \\
\hline CYP1A1 g. $6235 \mathrm{~T}>C(m 1)$ heterozygote & 0.72 & $0.48,1.08$ \\
\hline CYP1A1 g. $6235 \mathrm{~T}>\mathrm{C}(\mathrm{m} 1)$ allele (dominant) & 0.66 & $0.45,0.97$ \\
\hline CYP1A1 g. $6235 \mathrm{~T}>C$ (m1) allele (recessive) & 0.60 & $0.36,1.02$ \\
\hline CYP1A1 g.4889A >G $(m 2)$ homozygote & 0.84 & $0.33,2.17$ \\
\hline CYP1A1 g.4889A >G $(m 2)$ heterozygote & 0.66 & $0.44,0.99$ \\
\hline CYP1A1 g.4889A >G (m2) allele (dominant) & 0.66 & $0.46,1.00$ \\
\hline CYP1A1 g.4889A >G (m2) allele (recessive) & 0.97 & $0.38,2.48$ \\
\hline$N A T 1 * 3$ allele & 0.29 & $0.07,1.33$ \\
\hline$N A T 1 * 4$ allele & 0.87 & $0.60,1.27$ \\
\hline$N A T 1^{*} 10$ homozygote & 1.69 & $0.94,3.02$ \\
\hline$N A T 1 * 10$ heterozygote & 1.86 & $1.04,3.34$ \\
\hline$N A T 1^{*} 10$ allele (dominant) & 1.78 & $1.05,3.04$ \\
\hline$N A T 1^{*} 10$ allele (recessive) & 1.06 & $0.20,1.55$ \\
\hline$N A T 1^{*} 11$ allele & 2.06 & $0.86,4.95$ \\
\hline$N A T 2 * 4$ allele & 1.06 & $0.72,1.57$ \\
\hline$N A T 2 * 5 A$ allele & 1.80 & $0.11,28.9$ \\
\hline$N A T 2 * 5 B$ allele & 1.39 & $0.77,2.53$ \\
\hline$N A T 2 * 5 C$ allele & 0.22 & $0.03,1.77$ \\
\hline$N A T 2 * 6 B$ allele & 1.04 & $0.72,1.52$ \\
\hline NAT2*7Aallele & 1.00 & $0.67,1.50$ \\
\hline
\end{tabular}

Subgroup analyses of significant genotypes were also carried out. Comparing samples by GSTP1 genotype shows that heterozygosity for the $N A T 1^{*} 10$ allele confers risk among those who have only one or no copy of the GSTP1
c.313A>G allele (OR 2.2; 95\% CI 1.18-4.10) that is not seen among subjects that are homozygous for the GSTP1 c.313A $>\mathrm{G}$ allele (Table 5). However, when grouped according to $N A T 1^{*} 10$ status, the data suggests that the increased oral cancer risk conferred by GSTP1 c.313A $>\mathrm{G}$ homozygote genotype is significant among subjects who are homozygous for the $N A T 1^{*} 10$ risk allele (OR 8.8; 95\% CI 2.432.34) compared to other NAT1 genotypes (Table 5). When genotype subgroups were compared according to CYP1A1 genotype, susceptibility for oral cavity cancer due to GSTP1 c.313A $>\mathrm{G}$ homozygote genotype is more significant among subjects who have no or only one copy of the CYP1A1 g.6235T>C allele (OR 3.81; 95\% CI 1.6-9.04) (Table 5).

Table 4. Multivariate logistic regression analyses of genetic factors, all genotypes

\begin{tabular}{|c|c|c|}
\hline Variable $^{a}$ & OR & OR $95 \% \mathrm{CI}$ \\
\hline Constant & -- & -- \\
\hline Age & 1.06 & $1.04,1.08$ \\
\hline Male sex & 2.11 & $1.39,3.21$ \\
\hline \multicolumn{3}{|l|}{ GSTP1 wildtype } \\
\hline GSTP1 c.313A >G heterozygote & 0.90 & $0.58,1.38$ \\
\hline GSTP1 c.313A>G homozygote & 2.98 & $1.35,6.57$ \\
\hline \multicolumn{3}{|l|}{ CYP1A1 wildtype } \\
\hline CYP1A1 g.6235T >C heterozygote & 0.73 & $0.46,1.15$ \\
\hline CYP1A1 g.6235T>C homozygote & 0.45 & $0.24,0.85$ \\
\hline \multicolumn{3}{|l|}{ Non-NAT1*10 genotype } \\
\hline$N A T 1^{*} 10$ heterozygote & 2.15 & $1.16,3.96$ \\
\hline$N A T 1^{*} 10$ homozygote & 1.85 & $0.98,3.48$ \\
\hline
\end{tabular}

Once environmental variables were combined with genetic polymorphisms found to be significant in the multivariate logistic regression model, only the homozygote GSTP1 c.313A $>\mathrm{G}$ was shown to confer a significant threefold risk (OR 3.16; 95\% CI 1.32-7.59) for oral cavity cancer, along with environmental factors such as smoking (OR 2.77; 95\% CI 1.49-5.14), passive smoking (OR 2.79; 95\% CI 1.555.00 ), inverted smoking (OR 2.78; 95\% CI 1.06-7.32) and tobacco chewing (OR 4.50; 95\% CI 1.19-17.05) (Table 6). From the model, fish sauce (patis) consumption of at most 1x/month (OR $0.42 ; 95 \%$ CI 0.22-0.81), and shrimp paste (bagoong) consumption of at most $1 \mathrm{x} / \mathrm{month}$ (OR $0.44 ; 95 \% \mathrm{CI}$ 0.23-0.84) were still significantly protective (Table 6).

Table 5. Age- and sex-adjusted multivariate logistic regression analyses when grouped according to genotype

\begin{tabular}{lcccc}
\hline \multicolumn{1}{c}{ Genotype Group } & $\mathbf{N}$ & Genotype Tested & OR & OR 95\%CI \\
\hline $\begin{array}{l}\text { GSTP1 c.313A>G non- } \\
\text { homozygote }\end{array}$ & 353 & $\begin{array}{c}\text { NAT1*10 } \\
\text { Heterozygote }\end{array}$ & 2.20 & $1.18,4.10$ \\
$\begin{array}{l}\text { CYP1A1 g.6235T>C } \\
\text { non-homozygote }\end{array}$ & 404 & $\begin{array}{c}\text { GSTP1 c.313A>G } \\
\text { homozygote }\end{array}$ & 3.81 & $1.60,9.04$ \\
NAT1*10 Homozygote & 176 & $\begin{array}{c}\text { GSTP1 c.313A }>\mathrm{G} \\
\text { homozygote }\end{array}$ & 8.80 & $2.40,32.34$ \\
\hline
\end{tabular}


Table 6. Multivariate logistic regression analyses of genetic and environmental factors

\begin{tabular}{|c|c|c|}
\hline Variable $^{a}$ & OR & OR 95\%CI \\
\hline Constant & -- & -- \\
\hline Age & 1.06 & $1.04,1.07$ \\
\hline Male sex & 1.74 & $0.99,3.07$ \\
\hline GSTP1 c.313A>G homozygote & 3.16 & $1.32,7.59$ \\
\hline \multicolumn{3}{|l|}{ Non-smoker } \\
\hline Current smoker & 2.77 & $1.49,5.14$ \\
\hline Ex-smoker & 1.88 & $0.95,3.73$ \\
\hline Passive smoker & 2.79 & $1.55,5.00$ \\
\hline Tobacco chew & 4.50 & $1.19,17.05$ \\
\hline Inverted smoking & 2.78 & $1.06,7.32$ \\
\hline \multicolumn{3}{|l|}{ Non-fish sauce (patis)-eater } \\
\hline At most $1 \mathrm{x} /$ month & 0.42 & $0.22,0.81$ \\
\hline 1x/week - 2x/day & 0.62 & $0.32,1.21$ \\
\hline \multicolumn{3}{|l|}{ Non-shrimp paste (bagoong)-eater } \\
\hline At most $1 \mathrm{x} / \mathrm{month}$ & 0.44 & $0.23,0.84$ \\
\hline 1x/week - 2x/day & 0.99 & $0.51,1.92$ \\
\hline
\end{tabular}

\section{Discussion}

The environmental factors shown by multivariate analysis to be significantly associated with oral cavity cancer in our study: smoking (current, passive and inverted); and tobacco chewing (Table 2), are known to be strongly associated with oral cavity cancer in literature. ${ }^{1,32,33}$ On the other hand, environmental factors that were shown to be protective against oral cavity cancer among Filipinosconsumption of shrimp paste (bagoong) and fish sauce (patis)-have not yet been noted in previous studies. It is possible that fish sauce can serve as a source of polyunsaturated fatty acids (PUFAs), eicosapentaenoic acid (EPA) and docosahexaenoic acid (DHA) which have been demonstrated in a number of in vitro and animal experiments to inhibit the promotion and progression of cancer; however, our findings merit further investigation since fish sauce in the diet has also been found to increase risk for esophageal and gastric cancer in previous studies. ${ }^{34-38}$

From the GST alleles included in this study, only the GSTP1 polymorphism was found to be independently associated with oral cavity cancer among Filipinos. This polymorphism results in an Isoleucine to Valine substitution at position 105-close to the enzyme's binding site for electrophilic substrates. ${ }^{39}$ Unsurprisingly, the 105 Val variant of the enzyme has been demonstrated to exhibit altered affinity for electrophilic substrates. ${ }^{40}$ Apart from causing substrate dependent changes in enzyme activity, this polymorphism was also shown to be less stable than the 105Ile form and has been associated with higher levels of DNA adducts. ${ }^{17,41}$ Similar to the findings of this study, this GSTP1 polymorphism has been noted to be a risk factor for this particular cancer type in a meta-analysis and previous studies among Taiwanese and Caucasian subjects. ${ }^{6,42,43,44}$ It must be noted, however, that other genetic epidemiological studies conducted among Brazilians, Caucasians and one pooled analysis have found no association with GSTP1 genotype and oral cavity cancer risk. With regard to the null variants of GSTT1 and GSTM1, studies have demonstrated that homozygous deletion of either gene results in no functional activity of their respective enzyme. ${ }^{6,45-48}$ Since both enzymes are involved in phase II detoxification carcinogens present in tobacco smoke, pesticides and other environmental pollutants functional inactivity for either GSTM1 or GSTT1 could result in reduced carcinogen detoxification and excretion and a higher rate of DNAadduct formation, which could result in a higher risk for carcinogenesis. ${ }^{16}$ The deletion at the GSTM1 locus has been shown to be a significant risk factor in a number of studies among Japanese, Indian, Thai, and Asians. ${ }^{49-53}$ However, this study was unable to detect any significant associations between the GSTM1 and GSTT1 null genotypes and oral cavity cancer risk among Filipinos. Concurrently, many other molecular epidemiology studies have reported a lack of genotype-risk associations for homozygous GSTM1 deletions among Indian, Japanese, Korean, Taiwanese and Indonesian subjects, while a number of studies on the GSTT1null genotype have also reported no significant association with this cancer type among Indian, Japanese, Thai, Taiwanese, and Indonesian populations. $8,24,50,52,54-60$ However a recent meta-analysis suggested that the GSTT1 null genotype is a risk allele for oral cancer among Asians, but more studies are needed to confirm this finding. ${ }^{61}$

Correlating the CYP1A1 alleles and oral cavity cancer, published reports based on Indian, Japanese and Caucasian populations have identified the CYP1A1 $\mathrm{m} 2$ allele or $m 2 / \mathrm{m} 2$ genotype as a cancer risk factor; while the CYP1A1m1/m1 genotype, which has been identified in studies among Korean and Japanese subjects and in one meta-analysis to significantly increase risk for oral cancer, has been shown to be a significant protective factor in this study. ${ }^{8,24,49,58,62,63}$ One possible explanation for this discrepancy is that, among Filipinos, this allele is in linkage disequilibrium with a protective allele rather than with the functional allele, thereby producing the said results. On the other hand, a number of reports have been unable to detect significant associations with the $m 1$ and the $m 2$ alleles. $45,51,57,60,64$

Among the NAT variants, the NAT1*10 allele, has been reported to be a significant risk factor for oral squamous cellcarcinoma in a study conducted on a Japanese population. ${ }^{22}$ This particular allele is caused by two substitutions (g.1095C >A and g.1088T >A) in the 3' untranslated region of the gene, and has been associated with rapid acetylation both in vitro and in vivo. ${ }^{29,65}$ Our findings suggest that the presence of the allele as well as the $N A T 1^{*} 10$ heterozygote genotype increase oral cavity cancer susceptibility. Despite being noted to be risk factors for oral cavity cancer in previous reports, the NAT2 slow acetylating alleles $(N A T 2 * 5 A, N A T 2 * 5 B, N A T 2 * 6 B, N A T 2 * 7 A)$ were not found to be significant in our study. ${ }^{23,24}$ It must be noted that one 
limitation of our study is the select number of NAT1 and NAT2 alleles investigated in our population. For such genes exhibiting such high genetic variability, interrogating a larger number of polymorphisms will allow for a more accurate determination of acetylator status, and in turn make for better evaluation of risk associations.

Subgroup analyses with respect to GSTP1 c.313A>G, CYP1A1 g.6235G $>C$ and $N A T 1^{*} 10$ genotypes reveal that the effect of genotype combinations also reflect the oral cancer risk associations of the genetic factors when evaluated individually. When subjects were grouped according to $N A T 1^{*} 10$ status, susceptibility for oral cavity cancer among homozygotes for both $N A T 1^{*} 10$ and GSTP1 c.313A>G risk alleles increased almost nine fold. This increased disease susceptibility that is associated with combining risk genotypes implies a synergistic relationship among different gene variants. After stratifying according to CYP1A1 m1 allele status, the risk conferred by the homozygous GSTP1 c.313A $>\mathrm{G}$ genotype was more than threefold higher among subjects who lacked or possessed only one copy of the CYP1A1m1 allele-which was found to be protective in this study-whereas among subjects who had the CYP1A1 $m 1 / m 1$ genotype, the effect of GSTP1 c.313A>G was not significant.

After multivariate analysis of significant genetic and non-genetic variables, the CYP1A1 $m 1$ and NAT1*10 genotypes were no longer significantly associated with oral cavity cancer, suggesting that the risk modifying effect of the environmental factors - smoking, passive smoking, inverted smoking, tobacco chewing, patis and bagoong consumptionwere stronger relative to the effects of the CYP1A1 and NAT1 genes. The only gene variant that remained to be a significant risk factor for this cancer type was the homozygous GSTP1 c.313A $>\mathrm{G}$ genotype. Our findings suggest that this polymorphism may play a significant role in the genesis of oral cavity carcinomas and it would be useful to explore its association with environmental factors may be modulated by this genetic polymorphism; moreover GSTP1 is a good candidate as a risk modifier for oral cavity carcinoma since it is widely expressed in the oral cavity. ${ }^{66}$ As for the other genetic polymorphisms which were not significantly associated with oral cavity cancer, the lack of association detected by our study does not automatically discount the potential of these genetic factors as risk modifiers for this cancer type. A genetic epidemiological study having a much larger sample size and greater allele coverage may be needed to better assess the relationship of these genes with disease susceptibility. To our knowledge, this is the first study that investigates the genetic epidemiology of oral cavity cancer in the Filipino population. The data obtained from this study will certainly serve as a useful reference for further studies to be conducted on existing and future hypotheses regarding relationships and risk modifying effects of the genetic and environmental variables studied.

\section{Acknowledgments \\ The grant support for this research was provided by the Department of Science and Technology, the Philippine Council for Health Research and Development and the National Institutes of Health, University of the Philippines Manila.}

The Philippine Cancer Genetics Study Group: Drs. Maria Constancia Obrerro-Carrillo (Institute of Human Genetics), Virgilio Banez, Aileen David-Wang, Francisco Roxas, Orlino Bisquera, Jr., Alberto Roxas, Beatriz Tiangco, Elizabeth Nuqui, Arnold Fernandez, Cecilia Sison, Oliver Florendo, Albert Albay, Lakan Florenio Beratio, Richmond Ceniza, Eleanor Dominguez, Rosalyn HernandezSebastian, Leander Linus Philip Simpao, Luminardo Ramos (Philippine General Hospital), John Coloma, Higinio Mappala, Alex Tapia, Emmanuel Montana, Jonathan Asprer (Jose R. Reyes Memorial Medical Center), Rey Desales, Nelia Tan-Liu, Sullian SyNaval, Roberto Montevirgen, Catalina de Siena Dimayacyac, Pedrito Tagayuna (Lung Center of the Philippines), Reynaldo Joson, Sergio Paguio (Ospital ng Maynila), Conrado Cajucom, Andrew Dimacali, Richard Tia (Medical Center Manila), Tristan Chipongian, Joselito David, Florentino Doble, Noemi Pato (East Avenue Medical Center), Benito Bionat, Hans Francis Ferraris, Adonis Guancia, Eriberto Layda (Corazon Locsin Montelibano Memorial Regional Hospital Bacolod City). We would also like to acknowledge the individuals who worked on this project: Josef Misael Cortez, Feorillo Galivo, Ma. Rosanna Mendoza, Cindy Oarmata, Rhocile Lee Romblon, Gloriamaris Loy, Madonna Balbacal, Anna Kristina Serquina, Jane Mercado, Joren Bumacod, Edgar Tafaleng, Marife Arancillo, Fang-I Chao, Noelle Niña Gianan, William Augustine Roque, Iris Diana Uy, Geralyn Valleza, Julio Rodrigo Reyes, Jo Erika Narciso, Diana Victoria Doromal, Noel Francis Javellana, Nicie Gayle Fabros, Karl Cabalteja and Francis Tablizo. The authors would like to thank Roemel Jeusep Luna and Marjo Mendoza for preparing the final manuscript.

\section{References}

1. Boyle P, Levin B (eds.) World Cancer Report, Lyon: IARC Press. 2008.

2. Ferlay J, Shin HR, Bray F, Forman D, Mathers C, Parkin D. GLOBOCAN 2008, Cancer Incidence and Mortality Worldwide: IARC CancerBase No. 10. In. 2008.

3. Shields PG, Harris CC. Cancer risk and low-penetrance susceptibility genes in gene-environment interactions. J Clin Oncol. 2000; 18(11):23095.

4. Kotnis A, Sarin R, Mulherkar R. Genotype, phenotype and cancer: role of low penetrance genes and environment in tumour susceptibility. J Biosci. 2005; 30(1): 93-102.

5. Bartsch H, Nair U, Risch A, Rojas M, Wikman H, Alexandrov K. genetic polymorphism of cyp genes, alone or in combination, as a risk modifier of tobacco-related cancers. Cancer Epidemiol Biomarkers Prev. 2000; 9(1):3-28.

6. Hashibe M, Brennan P, Strange RC, et al. Meta- and pooled analyses of GSTM1, GSTT1, GSTP1, and CYP1A1 genotypes and risk of head and neck cancer. Cancer Epidemiol Biomarkers Prev. 2003; 12(12):1509-17.

7. Hein DW, Doll MA, Fretland AJ, et al. Molecular genetics and epidemiology of the NAT1 and NAT2 acetylation polymorphisms. Cancer Epidemiol Biomarkers Prev. 2000; 9(1):29-42. 
8. Sreelekha TT, Ramadas K, Pandey M, Thomas G, Nalinakumari KR, Pillai MR. Genetic polymorphism of CYP1A1, GSTM1 and GSTT1 genes in Indian Oral cancer. Oral Oncol. 2001; 37(7):593-8.

9. Frye RF. Probing the world of cytochrome p450 enzymes. Mol Interv. 2004; 4(3):157-62

10. Hong JY, Yang CS. Genetic polymorphism of cytochrome P450 as a biomarker of susceptibility to environmental toxicity. Environ Health Perspect. 1997; 105 Suppl 4:759-62.

11. Petersen DD, McKinney CE, Ikeya K, et al. Human CYP1A1 gene: cosegregation of the enzyme inducibility phenotype and an RFLP. Am J Hum Genet. 1991; 48(4):720-5.

12. Landi MT, Bertazzi PA, Shields PG, et al. Association between CYP1A1 genotype, mRNA expression and enzymatic activity in humans. Pharmacogenetics. 1994; 4(5):242-6

13. Zhuo XL, Ling JJ, Zhou Y, Zhao HY, Song YF, Tan YH. NAT2 polymorphisms with oral carcinoma susceptibility: a meta-analysis. Mol Biol Rep. 2012; 39(9):8813-9.

14. Townsend DM, Tew KD. The role of Glutathione-S-transferase in anticancer drug resistance. Oncogene. 2003; 22(47):7369-75.

15. Helzlsouer KJ, Selmin O, Huang HY, et al. Association between Glutathione S-Transferase M1, P1, and T1 genetic polymorphisms and development of breast cancer. J Natl Cancer Inst. 1998; 90(7):512-8.

16. Geisler SA, Olshan AF. GSTM1, GSTT1, and the risk of squamous cell carcinoma of the head and neck: a mini-HuGE review. Am J Epidemiol. 2001; 154(2):95-105.

17. Ryberg D, Skaug V, Hewer A, et al. Genotypes of Glutathione Transferase M1 and P1 and their significance for lung DNA adduct levels and cancer risk. Carcinogenesis. 1997; 18(7):1285-9.

18. Watson MA, Stewart RK, Smith GB, Massey TE, Bell DA. Human Glutathione S-transferase P1 polymorphisms: relationship to lung tissue enzyme activity and population frequency distribution. Carcinogenesis. 1998; 19(2):275-80.

19. Singh R, Haridas N, Shah F, Patel J, Shukla S, Patel P. Gene polymorphisms, tobacco exposure and oral cancer susceptibility: a study from Gujarat, West India. Oral Dis. 2014; 20(1):84-93.

20. Hein DW, Doll MA, Rustan TD, et al. Metabolic activation and deactivation of arylamine carcinogens by recombinant human NAT1 and polymorphic NAT2 Acetyltransferases. Carcinogenesis. 1993; 14(8):1633-8.

21. Sugamori KS, Wong S, Gaedigk A, et al. Generation and functional characterization of Arylamine N-Acetyltransferase NAT1/NAT2 doubleknockout mice. Mol Pharmacol. 2003; 64(1):170-9.

22. Katoh T, Kaneko S, Boissy R, Watson M, Ikemura K, Bell DA. A Pilot study testing the association between $\mathrm{N}$-acetyltransferases 1 and 2 and risk of oral squamous cell carcinoma in Japanese people. Carcinogenesis. 1998; 19(10):1803-7.

23. González MV, Alvarez V, Pello MF, Menéndez MJ, Suárez C, Coto E. Genetic Polymorphism of N-acetyltransferase-2, Glutathione Stransferase-M1, and Cytochromes P450IIE1 and P450IID6 in the susceptibility to head and neck cancer. J Clin Pathol. 1998; 51(4):294-8.

24. Morita S, Yano M, Tsujinaka T, et al. Genetic polymorphisms of drugmetabolizing enzymes and susceptibility to head-and-neck squamouscell carcinoma. Int J Cancer. 1999; 80(5):685-8.

25. Zhuo X, Zhao H, Chang A, et al. Cytochrome P450 1A1 Ile462Val polymorphism and oral carcinoma risk: an updated meta-analysis including 1,515 cases and 2,233 controls. Tumour Biol. 2012; 33(6):207989.

26. Hayashi SI, Watanabe J, Nakachi K, Kawajiri K. PCR detection of an A/G polymorphism within Exon 7 of the CYPlAl gene. Nucleic Acids Res. 1991; 19(17):4797.

27. Rumsby PC, Yardley-Jones A, Anderson D, Phillimore HE, Davies MJ. Detection of CYP1A1 mRNA levels and CYP1A1 MspI polymorphisms as possible biomarkers of exposure and susceptibility in smokers and non-smokers. Teratog Carcinog Mutagen. 1996; 16(1):65-74.

28. To-Figueras J, Gene M, Gomez-Catalan J, et al. Glutathione S-transferase M1 (GSTM1) and T1 (GSTT1) polymorphisms and lung cancer risk among Northwestern Mediterraneans. Carcinogenesis. 1997; 18(8):1529_ 33.
29. Bell DA, Stephens EA, Castranio $\mathrm{T}$, et al. Polyadenylation polymorphism in the Acetyltransferase 1 Gene (NATI) increases risk of colorectal cancer. Cancer Res. 1995; 55(16):3537-42.

30. Hubbard AL, Harrison DJ, Moyes C, et al. N-acetyltransferase 2 genotype in colorectal cancer and selective gene retention in cancers with chromosome 8p deletions. Gut. 1997; 41(2):229-34.

31. Department of Pharmacology and Toxicology U. o. L. Consensus Human Arylamine N-Acetyltransferase Gene Nomenclature [Online] 2008 [cited 2008]. Available from http://www.louisville.edu/medschool/pharmacology/NAT.html.

32. Hashibe M, Mathew B, Kuruvilla B, et al. Chewing tobacco, alcohol, and the risk of erythroplakia. Cancer Epidemiol Biomarkers Prev. 2000; 9(7):639-45.

33. Johnson N. Tobacco use and oral cancer: a global perspective. J Dent Educ. 2001; 65(4):328-39.

34. Dincer T, Cakli S, Kilinc B, Tolasa S. Amino Acids and Fatty Acid Composition Content of Fish Sauce. J Anim Vet Adv. 2010, 9, 311-315.

35. Larsson SC, Kumlin M, Ingelman-Sundberg M, Wolk A. Dietary longchain n-3 fatty acids for the prevention of cancer: a review of potential mechanisms. Am J Clin Nutr. 2004; 79(6):935-45.

36. Zajdel A, Wilczok A, Chodurek E, Gruchlik A, Dzierzewicz Z. Polyunsaturated fatty acids inhibit melanoma cell growth in vitro. Acta Pol Pharm. 2013; 70(2):365-9.

37. Ke L, Yu P, Zhang ZX. Novel Epidemiologic Evidence for the Association between Fermented Fish Sauce and Esophageal Cancer in South China. Int J Cancer. 2002; 99(3):424-6.

38. Ye WM, Yi YN, Luo RX, Zhou TS, Lin RT, Chen GD. Diet and gastric cancer: a case-control study in Fujian Province, China. World J Gastroenterol. 1998; 4(6):516-8.

39. Harries LW, Stubbins MJ, Forman D, Howard GC, Wolf CR. Identification of Genetic Polymorphisms at the Glutathione Stransferase Pi Locus and Association with Susceptibility to Bladder, Testicular and Prostate Cancer. Carcinogenesis 1997, 18, 641-644.

40. Zimniak P, Nanduri B, Pikula S, et al. Naturally occurring human glutathione S-transferase GSTP1-1 isoforms with isoleucine and valine in position 104 differ in enzymic properties. Eur J Biochem. 1994; 224(3):893-9.

41. Sundberg K, Johansson AS, Stenberg G, et al. Differences in the catalytic eefficiencies of allelic variants of Glutathione transferase P1-1 towards carcinogenic diol epoxides of polycyclic aromatic hydrocarbons. Carcinogenesis. 1998; 19:433-6.

42. Li W, Chen J, Liu C. Glutathione S-transferase P1 Ile105Val polymorphism and oral cancer risk: a meta-analysis. Int J Med Sci. 2013;10(4):392-8.

43. Chen MK, Tsai HT, Chung TT, et al. Glutathione S-transferase P1 and alpha gene variants; role in susceptibility and tumor size development of oral cancer. Head Neck. 2010; 32(8):1079-87.

44. Jourenkova-Mironova N, Voho A, Bouchardy C, et al. Glutathione Stransferase GSTM1, GSTM3, GSTP1 and GSTT1 Genotypes and the Risk of Smoking-related Oral and Pharyngeal Cancers. Int J Cancer. 1999; 81(1):44-8.

45. Leichsenring A, Losi-Guembarovski R, Maciel ME, et al. CYP1A1 and GSTP1 polymorphisms in an oral cancer case-control study. Braz J Med Biol Res. 2006, 39(12):1569-74.

46. Olshan AF, Weissler MC, Watson MA, Bell DA. GSTM1, GSTT1, GSTP1, CYP1A1, and NAT1 polymorphisms, tobacco use, and the risk of head and neck cancer. Cancer Epidemiol Biomarkers Prev. 2000, 9(2):185-91.

47. Zhong S, Howie F, Ketterer B, et al. Glutathione S-transferase mu locus: use of genotyping and phenotyping assays to assess association with lung cancer susceptibility. Carcinogenesis. 1991; 12(9):1533-7.

48. Pemble S, Schroeder KR, Spencer SR, et al. Human Glutathione Stransferase Theta (GSTT1): cDNA cloning and the characterization of a genetic polymorphism. Biochem J. 1994; 300 (Pt 1):271-6

49. Sato M, Sato T, Izumo T, Amagasa T. Genetic polymorphism of drugmetabolizing enzymes and susceptibility to oral cancer. Carcinogenesis. 1999; 20(10):1927-31.

50. Buch SC, Notani PN, Bhisey RA. Polymorphism at GSTM1, GSTM3 and GSTT1 gene loci and susceptibility to oral cancer in an Indian population. Carcinogenesis. 2002; 23(5):803-7. 
51. Anantharaman D, Chaubal PM, Kannan S, Bhisey RA, Mahimkar MB. Susceptibility to oral cancer by genetic polymorphisms at CYP1A1, GSTM1 and GSTT1 loci among Indians: tobacco exposure as a risk modulator. Carcinogenesis. 2007; 28(7):1455-62.

52. Kietthubthew S, Sriplung H, Au WW. Genetic and environmental interactions on oral cancer in Southern Thailand. Environ Mol Mutagen. 2001; 37(2):111-6.

53. Zhao SF, Yang XD, Lu MX, et al. GSTM1 null polymorphisms and oral cancer risk: a meta-analysis. Tumor Biol. 2013 1-7. doi:10.1007/s13277013-1037-z.

54. Shukla D, Dinesh Kale A, Hallikerimath S, Vivekanandhan S, Venkatakanthaiah Y. Genetic polymorphism of drug metabolizing enzymes (GSTM1 and CYP1A1) as risk factors for oral premalignant lesions and oral cancer. Biomed Pap Med Fac Univ Palacky Olomouc Czech Repub. 2012; 156(3):253-9.

55. Katoh T, Kaneko S, Kohshi K, et al. Genetic polymorphisms of tobaccoand alcohol-related metabolizing enzymes and oral cavity cancer. Int J Cancer. 1999; 83(5):606-9.

56. Tanimoto K, Hayashi SI, Yoshiga K, Ichikawa T. Polymorphisms of the CYP1A1 and GSTM1 gene involved in oral squamous cell carcinoma in association with a cigarette dose. Oral Oncol. 1999; 35(2):191-6.

57. Sugimura T, Kumimoto H, Tohnai I, et al. Gene-environment interaction involved in oral carcinogenesis: molecular epidemiological study for metabolic and DNA repair gene polymorphisms. J Oral Pathol Med. 2006; 35(1):11-8.

58. Cha IH, Park JY, Chung WY, Choi MA, Kim HJ, Park KK. Polymorphisms of CYP1A1 and GSTM1 genes and susceptibility to oral cancer. Yonsei Med J. 2007; 48(2): 233-9.

59. Hung HC, Chuang J, Chien YC, et al. Genetic polymorphisms of CYP2E1, GSTM1, and GSTT1 environmental factors and risk of oral cancer. Cancer Epidemiol Biomarkers Prev. 1997; 6(11): 901-5.

60. Amtha R, Ching CS, Zain R, et al. GSTM1, GSTT1 and CYP1A1 polymorphisms and risk of oral cancer: a case-control study in Jakarta, Indonesia. Asian Pac J Cancer Prev. 2009; 10(1):21-6.

61. Dong G, Tian Y, Chen S, Xu X, Zheng J, Li T. Glutathione S-transferase T1 null genotype is associated with oral cancer susceptibility in Asian populations. Tumour Biol. 2013; 34(3):1753-7.

62. Park JY, Muscat JE, Ren Q, et al. CYP1A1 and GSTM1 Polymorphisms and oral cancer risk. Cancer Epidemiol Biomarkers Prev. 1997; 6(10): 791-7.

63. Varela-Lema L, Taioli E, Ruano-Ravina A, et al. Meta-analysis and pooled analysis of GSTM1 and CYP1A1 polymorphisms and oral and pharyngeal cancers: a HuGE-GSEC review. Genet Med. 2008;10(6):36984.

64. Gattás GJ, de Carvalho MB, Siraque MS, et al. Genetic polymorphisms of CYP1A1, CYP2E1, GSTM1, and GSTT1 associated with head and neck cancer. Head Neck. 2006; 28(9):819-26.

65. Hein DW. Molecular genetics and function of NAT1 and NAT2: role in aromatic amine metabolism and carcinogenesis. Mutat Res. 2002; 506507:65-77.

66. Matthias C, Bockmühl U, Jahnke V. The Glutathione S-transferase GSTP1 polymorphism: effects on susceptibility to oral/pharyngeal and laryngeal carcinomas. Pharmacogenetics. 1998; 8(1):1-6. 